\title{
A Study on the Rapid Surface Staining of Fish Taste Buds
}

\author{
Sadao KIYOHARA, ${ }^{* 1}$ Junzoh KITOH, ${ }^{* 2}$ and Satoru YAMASHITA ${ }^{* 1}$ \\ (Accepted December 23, 1983)
}

\begin{abstract}
We previously reported that ponceau $\mathbf{S}$ or pontamine sky blue $6 \mathrm{~B}$ in trichloroacetic acid (TCA) selectively stains the taste pore region of taste buds in the minnow, carp, and blind cave fish. The present study was performed to elucidate the nature of this selective staining of fish taste buds.

The treatment of the tissues with TCA prior to staining was found to be essential to the visualization of the taste pores. A series of morphological and electrophysiological experiments suggests that the following process takes place: TCA penetrates the apical region of taste bud cells causing coagulation of proteinous substances and a change in the permeability of the apical membrane of the taste bud cells, and the dyes stain the apical part of buds rather than the extracellular material.
\end{abstract}

A method of selectively staining taste buds of intact tongues with dyes has been established in higher vertebrates such as the monkey, rat, and frog. ${ }^{1,2)}$ This method enables the location and counting of taste buds in the gustatory epithelium of animals in a simple and rapid way. It is known that the effective dyes, such as ponceau $S$, stain the extracellular material which fills the taste pore, rather than the apical tips of taste bud cells. ${ }^{23}$ The intensity of the staining color was shown to increase in general when the staining was made immediately after the tongues were stimulated with citric acid $(0.2 \mathrm{M})$ or quinine hydrochloride solutions $(0.05 \mathrm{M}){ }^{3}{ }^{3}$ This indicates that these solutions stimulate the secretory activity of taste bud cells.

In a previous paper, ${ }^{4}$ ) we applied this surface staining method to the taste buds of minnow Pseudorasbora parva, carp Cyprinus carpio, and blind cave fish Astyanax mexicanus, using various staining solutions, and have shown that ponceau $S$ or pontamine sky blue $6 \mathrm{~B}$ dissolved in TCA solution stains the taste pore region of the buds. The present study was designed to reveal the nature of the surface staining of fish taste buds.

\section{Material and Methods}

The minnow Pseudorasbora parva was used in this study. A staining test with $0.5 \%$ ponceau $\mathrm{S}$ and $0.5 \%$ pontamine sky blue $6 \mathrm{~B}$ dissolved in distilled water (D. W., pH 6.0) or a sodium phosphate buffer (SPB, pH 7 0) was first carried out on the upper lip bearing the respiratory valve after it was treated with various concentrations of TCA, $\mathrm{HCl}$, acetic acid, $\mathrm{NaCl}$, sucrose, quinine- $\mathrm{HCl}$, and proline for $0.1-15 \mathrm{~min}$. Since treatment of the tissue with TCA prior to staining was found to play an important role in marking the taste pore, the effects of TCA on the taste buds were examined morphologically and electrophysiologically.

The respiratory valve was fixed with ice cold fixative $^{4}$ after treatment with TCA. After postfixation with osmium tetroxide, the tissue was embedded in Epon and ultrathin sections were cut on a Porter-Blum MT-1 ultramicrotome. They were observed after staining with uranyl acetate and lead citrate under a JEOL $100 \mathrm{CX}$ electron microscope.

Taste responses to various concentrations of TCA were recorded from the minnow taste nerve innervating the upper lip region in order to elucidate the physiological effects of TCA on the taste buds. The procedures for obtaining the taste nerve preparation and recording its response were essentially the same as those described by KrYOHARA et al. ${ }^{5)}$ The electrical activity of the nerve was amplified with an r.c. amplifier and led into an electronic summator. Finally, it was displayed as the summated response on an inkwriting recorder. As taste stimulants, alanine, proline, $\mathrm{NaCl}$, quinine- $\mathrm{HCl}$, and $\mathrm{HCl}$ were also

*1 Biological Institute, College of Liberal Arts, Kagoshima University, Kagoshima 890, Japan (清原貞夫*

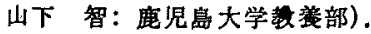

*2 Department of Anatomy, Nagoya University, School of Medicine, Nagoya 466, Japan（鬼頭純三：名古 屋大学医学部). 


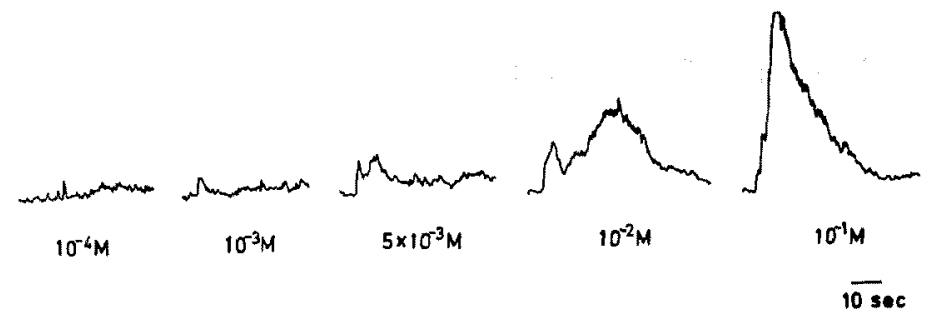

Fig. 1. Summated taste responses to various concentrations of TCA obtained from the palatine nerve of the minnow. The response to high concentrations of TCA is characterized by the appearance of a second peak. The response to $0.1 \mathrm{M}$ TCA saturated the capacity of the recorder. After application of $0.1 \mathrm{M}$ TCA on the upper lip, the responsiveness and spontaneous activity of the palatine nerve disappeared.

used.

In order to examine the extent of the penetration of the dye into the taste bud the respiratory valves were stained with ponceau $S$ in TCA, quickly frozen to the temperature of a dry ice-isopentane mixture, and placed in a freeze-drying unit for 4-7 days. After being dried, they were embedded in paraffin under varuum and sictioned at $6 \mu \mathrm{m}$.

\section{Results}

It was found that when the respiratory valve of the minnow was treated with TCA solution before staining, ponceau $\mathrm{S}$ or pontamine sky blue $6 \mathrm{~B}$ dissolved in D. W. or SPB could also stain the taste buds selectively as was seen when both the dyes were applied in TCA. The ability to stain taste buds with these dyes depended on both the duration of treament with TCA and its concentration; it was necessary to allow 20-25 min for $3 \times$ $10^{-3} \mathrm{M} \mathrm{TCA}, 10-15 \mathrm{~min}$ for $5 \times 10^{-3} \mathrm{M}, 3-5 \mathrm{~min}$ for $10^{-2} \mathrm{M}$, and $10-15 \mathrm{~s}$ for $10^{-1} \mathrm{M}$. Various taste solutions such as $\mathrm{HCl}\left(10^{-1}, 5 \times 10^{-2} \mathrm{M}\right)$, $\mathrm{NaCl}(0.5 \mathrm{M})$, quinine-HCl $\left(5 \times 10^{-2} \mathrm{M}\right)$, sucrose $(1 \mathrm{M})$, and proline $\left(10^{-1} \mathrm{M}\right)$, which have a marked stimulating effect on the lip taste receptors of the minnow ${ }^{b, b)}$ were used in place of the TCA as pretreatment chenicals. After the application of these chemicals on the lip region for $1-15 \mathrm{~min}$, the taste buds reacted with neither ponceau $S$ nor pontamine sky blue $6 \mathrm{~B}$ in $\mathrm{D}$.W.

Fig. 1 illustrates the summated response of the palatine taste nerve to TCA of varying concentrations. The threshold concentration was below $10^{-3} \mathrm{M}$ and the response increased in magnitude with increasing concentration. The response at higher concentrations was characterized by the appearance of a second response, following the initial phasic response. This response developed rather slowly at $5 \times 10^{-3} \mathrm{M}$ and lasted for a long period even after the receptors had been repeatedly rinsed with D.W. After the application of $10^{-1} \mathrm{M}$ TCA which elicited a remarkable response, as seen in the figure, the resporisiveness and background activity of the receptors disappeared; indicating irreversible damage to the preparation by the TCA. When a prolonged stimulation with $10^{-3} \mathrm{M}$ or $5 \times 10^{-3} \mathrm{M}$ TCA was applied to the receptors, a small phasic response first appeared leading to a gradual increase in the baseline activity. This was followed by a remarkable bursting of the taste fibers and finally the loss of responsiveness.

Our preliminary examination of the normal taste buds $^{7)}$ shows that, as in other fishes, ${ }^{8-11}$ the minnow taste bud contains two types of cells reaching the taste pore surface. One is generally called the light cell or t-cell, which has a thick rod-shaped apical process at the apex and tortuously tangled tubules in the supranuclear region. The other is called the dark cell or f-cell, which has microvilli at the apex and is characterized by longitudinally arranged microtubules, bundles of filaments and electron opaque granules. The microvilli are decorated by disk-shaped material which is similar to the elements seen in the electron opaque granule, suggesting secretory activity of the f-cell.

Figs, 2 and 3 show electron micrographs of a minnow taste bud treated with $10^{-2} \mathrm{M}$ TCA for $5 \mathrm{~min}$, during which time the full loss of the physiological response was considered to have occurred. The most prominent ultrastructural change in the treated taste buds was the appearance of vacuolated spaces in the cytoplasm of both types of cells and between adjacent cells possibly caused by concomitant shrinkage of the cytoplasm. The spaces, developed especially in the apical and lateral portion of the buds, contained various sizes of vacuoles and other membranous debris. In the apical re- 


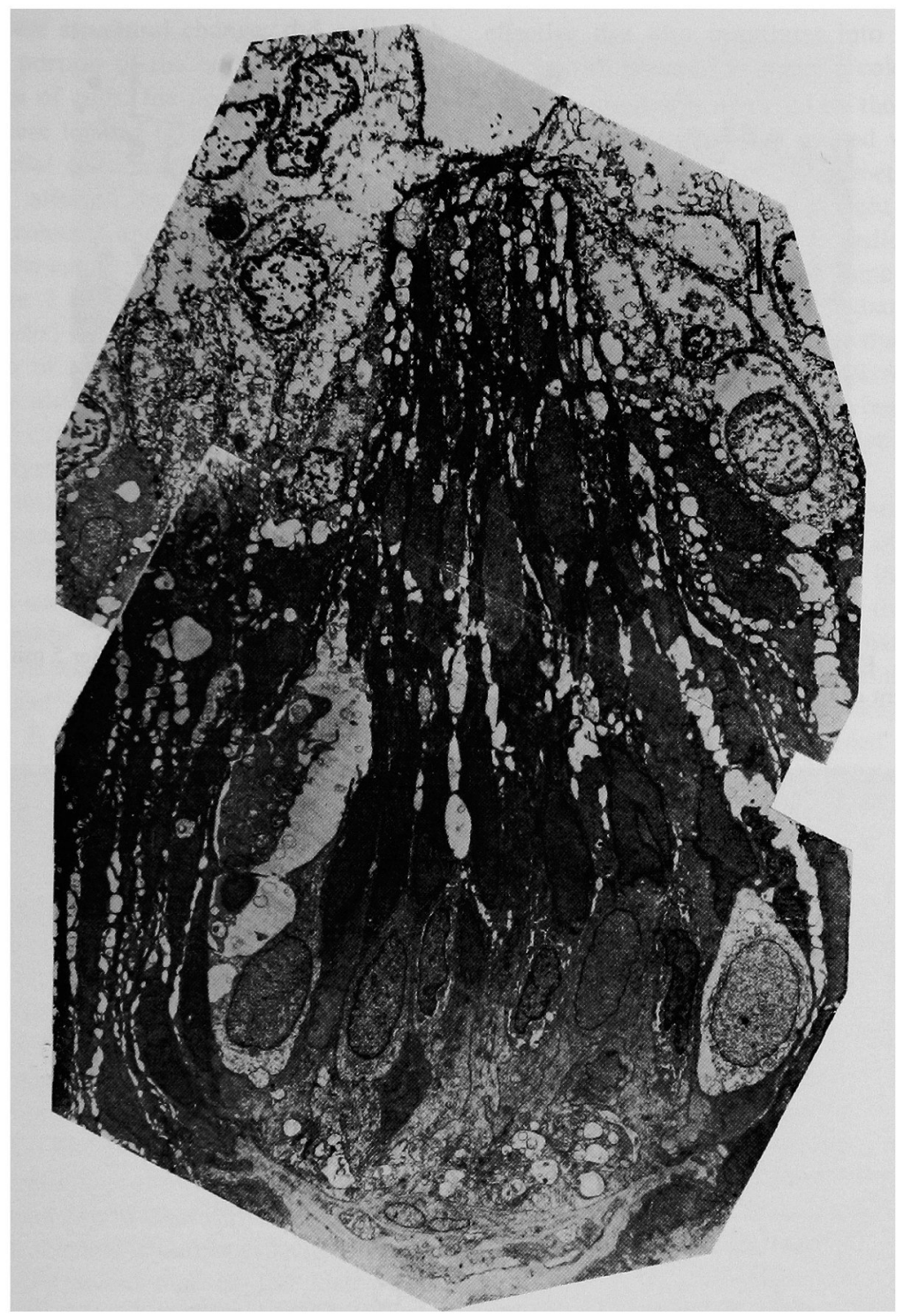

Fig. 2. Oblique section through the taste bud on the minnow respiratory valve prepared after treatment of the upper lip with $0,01 \mathrm{M}$ TCA for $5 \mathrm{~min}$; montage of two transmission electron micrographs. Scale line $5.0 \mu \mathrm{m}$.

gion, the cytoplasm of the f-cells was more electron dense except for the vacuolated spsce than that of normal cells, suggesting a considerable shrinkage of cytoplasmic material. The tubules of the t-cells appeared to swell. These features of the treated cells frequently prevented one from identifying the morphological characteristics of both types of cells However, the apical processes of the two cells, thouhg both of which became rather slender, and the tight junctional complexes between the adjacent cells were still detectable (Fig.
3). The direct opening of the intercellular or vacuolated spaces to the apical surface was not observed. A small amount of extracellular material was observed in some photographs and that of the treated taste buds was more electron dense than the normal buds. But in most cases (Fig. 3) the material was not detected. Its preservation was more difficult in the treated buds than in the normal ones. In the supranuclear region, filament bundles, microtubules, and mitochondria were detectable, but with somewhat increasing electron 


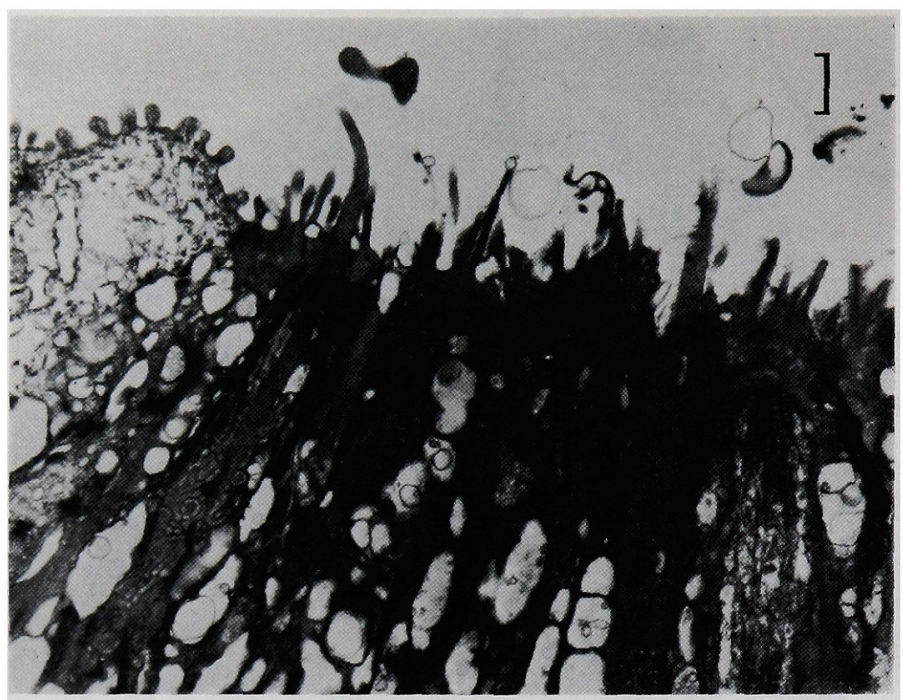

Fig. 3. Electron micrograph of the apical region of minnow taste buds prepared after 5 min treat ment of the upper lip with $0.01 \mathrm{~m}$ TCA. Scale line $1.0 \mu \mathrm{m}$.
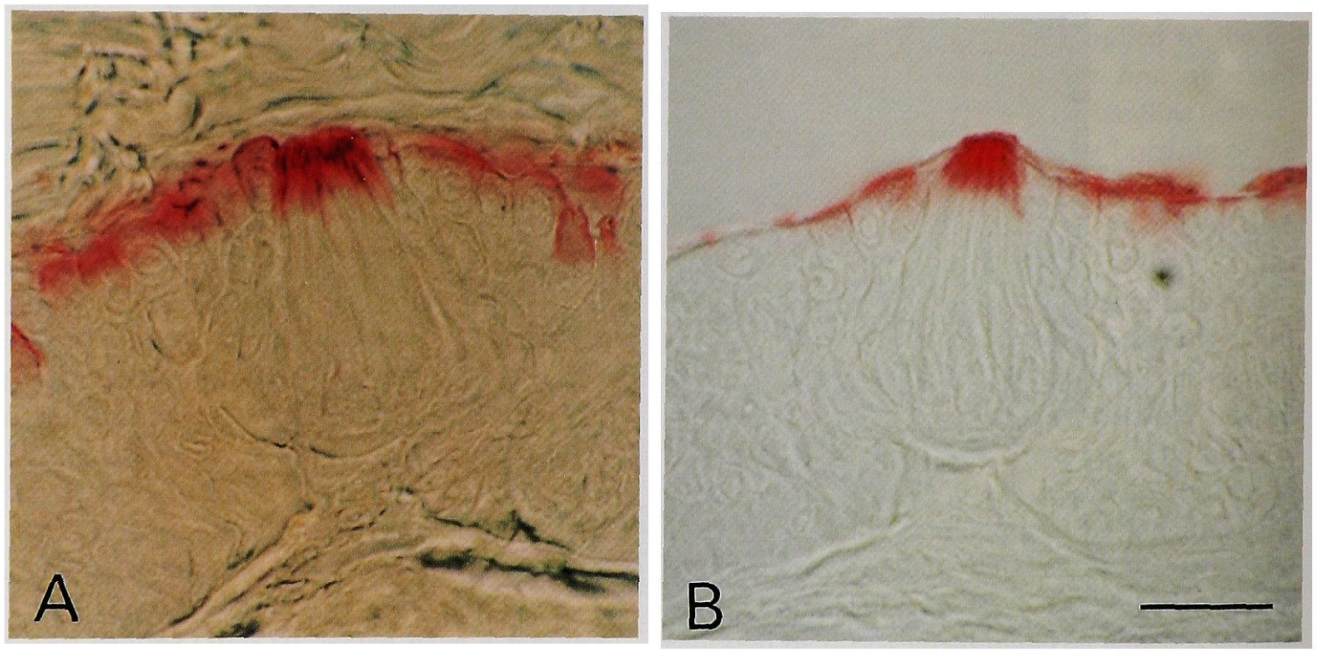

Fig. 4. Longitudinal section of the taste bud on the respiratory valve of minnow. A is not dewaxed and $\mathbf{B}$ is de-waxed. The section was made as follows in order to reveal the degree of penetration of the dye into the taste buds; the respiratory valve was stained with $0.5 \%$ ponceau $\mathrm{S}$ in TCA and quickly frozen with dry ice-isopentane mixture. Then, the tissue was placed in a freeze-drying unit for 4-7 days and embedded in paraffin under vacuum. The block was sectioned at $6 \mu \mathrm{m}$. The sections were stuck directly to glass slides and photographed without removal of paraffin wax (A) or after de-wax with xylene (B). Notice that the extent of penetration of the ponceau $\mathrm{S}$ into the taste buds does not differ between $\mathrm{A}$ and $\mathrm{B}$, indicating that diffusion of the dye during de-wax is not significant. Scale line $20 \mu \mathrm{m}$. 
opacity. These structural changes did not reach to the basal portion of the buds where nuclei of the two types of cells, the nerve plexus, and the basal rells were located (Fig. 2).

The epithelial cells near the surface were also considerably affected by the treatment. They became electrolucent and consisted of breakdown products of the cytoplasm and fragmented nuclear material (Figs. 2 and 3). The microridges of the surface epithelial cells were sometimes lost and an accumulation of electron-dense material was observed on the surface.

In order to examine which part of the taste bud the effective dyes stain, the respisatory valves which were clearly stained with ponceau S in TCA were frozen by immersion in dry ice-isopentane and freeze-dried. Then the dried tissue was infiltrated with paraffin wax and sectioned. Fig. 4 displays photomicrographs of two sections across the taste buds in the respiratory valve The former (A) is not de-waxed while the latter (B) is de-waxed with xylene. It is evident from this figure that the dye penetrates into the apical region of taste buds to some extent.

\section{Discussion}

The present study indicates that the treatment of fresh tissues with TCA solution before staining is essential to the visualization of fish taste buds. After sufficient treatment with TCA, the taste pore region of the taste buds was selectively stained with ponceau $\mathrm{S}$ or pontamine sky biue $6 \mathrm{~B}$ dissolved in D W. or SPB. The electrophysiological and morphological experiments showed that the treatment with TCA caused loss of responsiveness of the taste receptors and marked changes especially in the structures of the apical part of the taste buds (Figs. 1-3), indicating that TCA is an extremely irritating stimulus for taste buds. The dye was found to penetrate and react with the cytoplasmic material of the apical part of taste buds (Fig 4). TCA is used as a component of fixative mixtures and its effects on the fresh tissue have been also studied; it penetrates rather rapidly into the tissue, causing the coagulation of proteins. ${ }^{12)}$ Therefore, our staining method of fish taste buds with ponceau $S$ or pontamine sky blue $6 \mathrm{~B}$ in TCA consists of the following processes: 1 , TCA penetrates into the taste buds; 2 , during the penetration TCA causes a change in the permeability of the membrane of the protruding tips of taste bud cells and the coagulation of proteinaceous material; 3 , the effective dye also penetrates into the buds and reacts with material to make a colored dot.

The colored dots observed on the surface of the minnow respisatory valve stained with the effective dye in TCA ranged in diameter from 14 to $25 \mu \mathrm{m} .4)$ On the other hand, light microscopical observation of epon sections indicated that the diameter of taste pores on the same region ranged from 6.9 to $10.3 \mu \mathrm{m}$. Thus, the diameter of colored dots is to some extent greater than that of taste pores. This finding can be explained in terms of an increase in the volume of taste buds treated with TCA and the penetration of the dye into the apical part of buds.

In contrast to the present study, previous studies $^{2,3}$ on the surface staining of taste buds of higher vertebrates have revealed that ponceau $\mathrm{S}$ stains the extracellular material in the taste pore to visualize the buds. It was found that after application of citric acid $(0.5 \mathrm{M})$ or quinine- $\mathrm{HCl}(0.1 \mathrm{M})$ to the tongue of the rat and monkey, the pores of buds on the papillae were stained stronger with poncean $S$ in SPB than those on a control part of the same tongue. This is interpreted to be due to the fact that the taste substances stimulate the secretory activity of taste bud cells as was demonstrated earlier by MATteRn and PARAN. ${ }^{13)}$ They observed by means of an epimicroscope that fluid was secreted from the pore of the mouse taste bud immediately after application of $\mathrm{HCl}$ vapor on the tongue. The minnow taste buds also have extracellular material as mentioned previously ${ }^{4}$ and it is likely that they secrete the material in response to strong stimuli. In the present study, however, taste solutions of $0.1 \mathrm{M}$ $\mathrm{HCl}, 1.0 \mathrm{M} \mathrm{NaCl}, 0.05 \mathrm{M}$ quinine- $\mathrm{HCl}$, and $0.1 \mathrm{M}$ proline; which have marked stimulating effects on the taste receptors, ${ }^{5,0)}$ were not effective as pretreatment solutions to strengthen the staining of taste buds with the dye. This fact may be attributed simply to the lack of either the amount of extracellular material secreted or its reactivity to the dye. In connection with this secretion by the taste bud cells, it should be noted that fish taste buds do not have such an elaborate apical space to preserve the extracellular material on the surface like the taste pit observed in mammals. ${ }^{14)}$

\section{Acknowledgements}

We wish to thank Drs. J. CAPrio, Lousiana State University, and I. HrdakA, Mie University, for their valuable comments on the manuscript. 


\section{References}

1) H. Berkhoudt: Neth. J. Zool., 27, 310-331 (1977).

2) J. N. Brouwer and A. Wiersma: Histochemistry, 58, 145-151 (1978).

3) J. N. BRouWer and A. WIERSMA: in "Olfaction and Taste VII" (ed. van der Starre), IRL Press Ltd, London \& Washington DC, 1980, pp. 179182.

4) S. Kryohara, S. Yamashita, and J. Krtoh: Bull. Japan. Soc. Sci. Fish., 50, 1293-1297 (1984).

5) S. KTYohaRa, S. Yamashita, and S. HaRada: Physiol. Behav., 26, 1103-1108 (1981).

6) T. Kaku, M. Tsumagari, S. KiYohara, and S. YaMASHITA: Physiol. Behav., 25, 99-105 (1980).

7) S. Kryohara, S. Yamashita, and J. Kitoh: in "Olfaction and Taste VII" (ed. by van DER STARRE),
IRL Press Ltd, London \& Washington DC, 1980 , p. 204.

8) Y. Hirata: Arch histol. jap., 26, 507-523 (1966).

9) K. ReUtTER: Z. Zellforsch., 120, 280-308 (1971).

10) M. CRISP, G. A. LoWE, and M. S. LAVERACK: Tissue Cell, 7, 191-202 (1975).

11) N. Grover-Johnson and A. I. Farbman: Cell Tiss. Res., 169, 395-403 (1976).

12) J.A. Kiernan: Histological \& Histochemical Methods: Theory \& Practice, Pergamon Press, 1981, pp. 8-24.

13) C. F. T. Mattern and N. Paran: Exp. Neurol, 44, 461-469 (1974).

14) R. G. MurRaY: in "The Ultrastructure of Sensory Organs" (ed. by I. FriedmanN), North-Holland and American Elsevier Pub. Comp., 1973, pp. $1-81$. 